\title{
Influence of Environmental Conditions on Spore Production and Budding in Taphrina deformans, the Causal Agent of Peach Leaf Curl
}

\author{
V. Rossi and L. Languasco
}

Institute of Entomology and Plant Pathology, "S. Cuore" Catholic University, Via E. Parmense 8429100 Piacenza, Italy. Accepted for publication 20 September 2006.

\begin{abstract}
Rossi, V., and Languasco, L. 2007. Influence of environmental conditions on spore production and budding in Taphrina deformans, the causal agent of peach leaf curl. Phytopathology 97:359-365.

Environment-controlled studies were carried out to determine the growth of Taphrina deformans under different conditions of temperature, humidity, and nutrient availability similar to those found on plant surfaces during the peach-growing season. Both ascospores and blastospores were able to bud at all temperatures tested $\left(5\right.$ to $\left.37^{\circ} \mathrm{C}\right)$, with the optimum at 14 and $21^{\circ} \mathrm{C}$, respectively. Temperature $<20^{\circ} \mathrm{C}$ favored ascospore production and release, with the optimum at $10^{\circ} \mathrm{C}$. Budding was approximately two-

$100 \%$ relative humidity, and blastospores also maintained a certain budding ability at lower humidity levels (minimum tested $=47 \%$ ). Both spore types did not bud after $\approx 50$ to $55 \mathrm{~h}$ in the absence of external nutrients. In the presence of a periodically renewed carbon source, such as simple sugars, at concentrations that typically are present on peach plant surfaces, the fungus maintained its budding capability over time. Results showed that $T$. deformans is able to bud profusely under a wide range of environmental conditions that occur on peach tree surfaces. This work supports the hypothesis that $T$. deformans is a part of the normal epiphytic mycoflora of peach trees throughout the entire growing season.
\end{abstract} and-a-half times higher in a film of water than on a dry substrate, with
Additional keywords: life cycle, Prunus persica, saprophytic growth.
Taphrina deformans (Berk.) Tul. is a biotrophic parasitic fungus that causes leaf curl of peach (Prunus persica L.), a worldwide disease that is potentially devastating to both crop yield and tree longevity (37). T. deformans has a dimorphic life cycle, with a parasitic and a saprophytic phase (1). The parasitic phase starts when spores, in the presence of young host tissue, initiate infection by producing a hypha that penetrates the cuticle and invades the host tissue between the epidermal and the parenchyma cells (33). The parasitic phase culminates with the homothallic production of a compact, feltlike layer of naked asci erupting from the cuticle $(6,34)$. Ascospores are discharged in late spring or early summer; usually, they do not cause secondary infections but initiate the yeastlike saprophytic phase, producing blastospores by budding (33). Blastospores overwinter and cause infection the following spring.

The fate of the fungus from the time the ascospores are discharged until the establishment of infection in the following year is not completely understood. Because blastospores are able to bud readily in very dilute nutrient solutions, Fitzpatrick (17) argued that a certain amount of growth is possible on plant surfaces whenever they are wet for an extended period, so that the fungus becomes part of the normal surface mycoflora of peach trees. Investigations by Caporali (10) led to this hypothesis; this author (10) also suggested that rainfall during the autumn probably favors spore displacement within the tree (12). Lorenz (29), on the contrary, did not observe appreciable fungal growth in washings from peach leaves, whereas the fungus was able to bud during the entire vegetative period on the shoot tips.

Knowledge of the behavior of $T$. deformans during the nonpathogenic phase is crucial for understanding the life cycle,

Corresponding author: V. Rossi; E-mail address: vittorio.rossi@ unicatt.it

DOI: 10.1094/PHYTO-97-3-0359

(C) 2007 The American Phytopathological Society spread, and periods when the infection sites are colonized by the fungus. It has been demonstrated that spring infections are caused by inoculum already present in the buds at bud break (39), and that bud scales are the most important niches occupied by $T$. deformans cells $(7,32,43)$. Based on research of Fitzpatrick (17) and Caporali (10), blastospores arising from epiphytic $T$. deformans colonies must be dispersed by rain splash from other plant parts to bud scales after buds have formed. According to Lorenz (29), only the ascospores lodged on shoot tips continued to bud, so that they covered shoot tips and kept pace with growth of the host all season.

The objective of this study was to determine the ability of T. deformans to grow epiphytically under a range of conditions of temperature, humidity, and nutrient availability that occur on peach plant surfaces.

\section{MATERIALS AND METHODS}

All experiments were conducted by using the $T$. deformans strain MUCL 30957 from the BCCM/MUCL (Université Catholique de Louvain, Louvain-La-Neuve, Belgium).

Ascospore production. Buds of 20 potted, 3-year-old peach plants of cv. Early Maycrest were inoculated just before bud break by painting a blastospore suspension with a fine brush (18). Methods for preparing the blastospore suspension are described below. The plant surface was kept wet with a mist of water for $48 \mathrm{~h}$ at $10^{\circ} \mathrm{C}$ and then incubated at $15^{\circ} \mathrm{C}$ and 95 to $100 \%$ relative humidity (RH), under $12 \mathrm{~h}$ of light and $12 \mathrm{~h}$ of dark, until asci were produced on curled leaves (39). Leaves showing curl symptoms were collected from these plants soon after the first asci appeared. Collected leaves were homogeneous for both leaf age and time of disease onset.

Leaf discs (2.5 $\mathrm{cm}$ in diameter) with a uniform layer of asci were cut with a cork borer and affixed to the inside surface of the top of boxes made of transparent plexiglass ( 12 by 12 by $12 \mathrm{~cm}$ ), 
having the sporulating surface downward. Petri dishes $(9 \mathrm{~cm}$ in diameter) containing water agar (agar RM201 at 15 g/liter; Himedia Laboratories, Mumbai, India), were placed on the bottom of the box, over a sponge-cloth wetted with water to maintain $100 \% \mathrm{RH}$, so that the ascospores released from asci fell onto the agar. Boxes were placed in incubators at $5,10,15,20$, and $25^{\circ} \mathrm{C}$ (four boxes per temperature regime, one leaf disc per box) for 7 days with $12 \mathrm{~h}$ of light and $12 \mathrm{~h}$ of dark. Petri dishes were replaced with new dishes at 24-h intervals. After the seventh day, the experiment was stopped because the leaves were no longer turgid and ascospore discharge became inconsistent. The dishes were removed and incubated at $20^{\circ} \mathrm{C}$ to favor growth of colonies from the ascospores that had landed on the agar. In preliminary experiments, the presence of many overlapping fungal colonies made their enumeration impossible. Therefore, grids of circular plastic sheets ( $9 \mathrm{~cm}$ in diameter) with 52 holes ( $2 \mathrm{~mm}$ in diameter), regularly spaced, were made and placed over the petri dishes during exposure to discharged ascospores so that, in this way, fungal colonies were easily enumerated after incubation. Relative ejection was expressed as the number of colonies growing from ejected spores divided by the maximum possible number of colonies (i.e., the number of holes in the grid). The experiment was repeated three times.

Spore budding. These experiments were carried out using suspensions of blastospores and ascospores. Blastospores were obtained by culturing the fungus on potato dextrose agar (PDA; $4 \mathrm{~g}$ of potato extract, $20 \mathrm{~g}$ of glucose, and $39 \mathrm{~g}$ of agar CM 0139 per liter) (Oxoid Ltd., Basingstoke, UK), pH 5.6, for 7 days at $23 \pm 2^{\circ} \mathrm{C}$. At the end of incubation, the colonies were dispersed gently in distilled water to obtain a blastospore suspension. Ascospores were obtained from leaves showing fungal sporulation that had been inoculated as previously described. Leaf discs with abundant asci were soaked gently in distilled water to release ascospores, and the resulting suspension was filtered through a double layer of cheesecloth. It has been demonstrated that some ascospores can begin asexual multiplication inside the ascus (50); therefore, it is likely that there was a small number of blastospores in the suspensions of ascospores derived from asci.

Both blastospore and ascospore suspensions were adjusted to $\approx 7 \times 10^{6}$ spores $/ \mathrm{ml}$. These suspensions were grown under different conditions of temperature, humidity, and nutrient availability, with nine replicates per treatment. At the end of each experiment, three groups of 100 spores per replicate were observed microscopically $(\times 250)$ and each spore was classified as budding or not. The same measurement was made at the beginning of each experiment, to test the frequency of budding spores in the original suspension. The mean proportion of budding spores then was calculated for each treatment and replicate by subtracting the average proportion of budding spores at the beginning of the experiment from each final value. All experiments were performed twice.

To test the effect of temperature ( $\mathrm{T}$ ) on spore budding, nine $10-\mu \mathrm{l}$ drops of spore suspension were deposited in the circular wells $(\approx 13 \mathrm{~mm}$ in diameter and $0.5 \mathrm{~mm}$ deep) of depression slides. Slides were placed in petri dishes over wet blotting paper. Dishes were covered and sealed with parafilm to maintain $100 \%$ $\mathrm{RH}$, and incubated at $0,3,5,10,15,20,25,30,33,35$, or $37^{\circ} \mathrm{C}$ for $12 \mathrm{~h}$. Each drop then was observed microscopically and the proportion of budding spores was calculated as previously described.

The effect of humidity was tested in two experiments with blastospores. In the first, budding in water was compared with that on a dry substrate. For budding in water, nine 10- $\mu$ d drops of the blastospore suspension were deposited in depression slides as previously described. For dry conditions, blastospores were collected with a brush from colonies grown on PDA and deposited on microscope slides; this procedure was replicated nine times. Both depression and microscope slides were placed in petri dishes as previously described to maintain $100 \% \mathrm{RH}$ and incubated at 5, $10,15,20,25,30$, or $37^{\circ} \mathrm{C}$ for $12 \mathrm{~h}$. The proportion of budding blastorpores then was determined as previously described.

In a second experiment, the effect of different $\mathrm{RH}$ regimes was tested. Blastospores were placed on microscope slides with a brush and incubated at $20^{\circ} \mathrm{C}$ and at $47,78,84,95,97$, or $100 \%$ $\mathrm{RH}$ for $12 \mathrm{~h}$. To obtain the different $\mathrm{RH}$ levels, the slides were placed in boxes sealed with parafilm, with $200 \mathrm{ml}$ of water (100\% RH) or saturated salt solutions (15). Maintenance of the defined $\mathrm{RH}$ levels was recorded by data loggers (Tinytag Plus, Gemini Data Loggers Ltd., Chichester, UK). Microscopic observations were performed as previously described and the proportion of budding blastospores calculated.

To test the effect of nutrient availability, a preliminary experiment was performed by testing the dynamics of spore budding over time in the absence of external nutrient sources. Ascospore and blastospore suspensions ( $2 \mathrm{ml}$ per test tube) were placed on a rotating shaker $(50 \mathrm{rpm})$ and incubated at $20^{\circ} \mathrm{C}$ in the dark for 2 , $4,6,8,10,18,24,30,36$, or $48 \mathrm{~h}$ (three replicate tubes per treatment). At the end of incubation, three 10- $\mu$ d drops were drawn from each tube, placed on a microscope slide, and observed microscopically to determine the proportion of budding spores, as previously described.

To test the ability of the fungus to grow using the nutrients available on peach tree surfaces, blastospores were cultured in solutions containing different concentrations of carbon sources. A basic solution was prepared using a mixture of the prevalent sugars present in peach leaves and fruit, at their proper concentrations $(16,20,35,48): 1.191 \mathrm{~g}$ of sorbitol, $0.397 \mathrm{~g}$ of sucrose, $0.117 \mathrm{~g}$ of glucose, and $0.136 \mathrm{~g}$ of fructose per liter. This basic solution then was adjusted to the different concentrations found on the surfaces of leaves that have been examined $(31,45)$, on peach fruit (20), and in exudates from peach foliar nectaries (8): $\times 10^{-3}, \times 10^{-2}, \times 10^{-1}, \times 1, \times 10$, and $\times 10^{2}$. Thiamine, an essential vitamin that cannot be synthesized by this fungus (28) and is present on peach leaf surfaces (29), was added to each solution at $100 \mu \mathrm{g}$, as well as $2 \mathrm{~g}$ of proline per liter (40).

In the first experiment, the spore suspension was put in test tubes (three replicate tubes per treatment) with the different nutrient solutions $(0.1 \mathrm{ml}$ of spore suspension in $4 \mathrm{ml}$ of nutrient solution) and maintained in such nutrient conditions for the entire duration of the experiment. In a second experiment, the spore suspensions grown in the above-mentioned nutrient solutions were transferred to new nutrient solutions $(0.1 \mathrm{ml}$ of spore suspension in $2 \mathrm{ml}$ of nutrient solution) after $12,24,36,48,60$, and $72 \mathrm{~h}$, to mimic the renewal of the nutrient availability that likely occurs on the plant surfaces because of a progressive leakage of substances. In both experiments, suspensions were incubated at $20^{\circ} \mathrm{C}$ in the dark for $6,12,24,48,72$, or $96 \mathrm{~h}$, and continuously shaken $(50 \mathrm{rpm})$. At the end of each incubation period, three $10-\mu \mathrm{l}$ aliquots were drawn from each tube and examined as previously described to determine the proportion of budding spores.

Data analyses. All statistical analyses were performed using SPSS (version 11.5; SPSS Inc., Chicago). Percentages of budding blastospores were transformed into relative values by dividing each value by the maximum observed in each experiment.

Nonlinear regression analysis was used to fit data from controlled-environment experiments: relative budding was regressed against time of incubation, $\mathrm{T}$, or $\mathrm{RH}$ regimes using the $\beta$ function $Y=\left(a \times X^{b} \times[1-X]\right)^{c}(2)$, the logistic $Y=c /(1+\exp [a-b \times X])$ (9), or the asymptotic $Y=k\left(a-b \times c^{\sqrt{(100-x)}}\right)$ (14), where $Y$ and $X$ are the dependent and independent variables, respectively, the latter being T, RH, days or hours of incubation, depending on experiment; $a, b$, and $c$ are the model parameters; and $k$ is a constant. The $\beta$ function has been developed by Analytis (2) to fit relationships between biological development of plant-pathogenic fungi and temperature. As independent variable $(X)$ it uses the ratio $(\mathrm{T}-\mathrm{Tmin}) /(\mathrm{Tmax}-\mathrm{Tmin})$, where $\mathrm{Tmin}$ and $\mathrm{Tmax}$ are mini- 
mum and maximum levels of T, respectively, when $Y$ is equal to zero. When these two values were outside the range of tested values, they were determined based on the goodness of fit. Goodness of fit was evaluated through the standard error of parameters and distribution of actual data versus the estimated data points, residual mean square $\left(\mathrm{MS}_{\mathrm{RES}}\right)$ and adjusted coefficient of determination $\left(R_{\mathrm{adj}}{ }^{2}\right)(14)$, and number of iterations taken by the Marquardt algorithm to converge on parameter estimates (38).

Data from repeated experiments first were fitted separately; afterward, they were aggregated because the estimated equation parameters for the first experiment were within the calculated standard errors for the repeated ones (data not shown).

A factorial analysis of variance (ANOVA) was performed to test the effect of nutrient availability and incubation time on relative budding. The Fisher protected least significant difference (FLSD) was used to separate means at $P=0.05$ (14).

\section{RESULTS}

Effect of temperature on ascospore production. The relative proportion of $T$. deformans colonies growing from ascospores produced and discharged from asci increased up to day 5 of incubation and then remained at a high level until day 7, according to the fitted logistic model (Table 1; Fig. 1A); after this time, the detached leaves lost turgidity and spore discharge became inconsistent. After 7 days of incubation, spore discharge was maximum at $10^{\circ} \mathrm{C}$, diminished by approximately one-third at 5 and $15^{\circ} \mathrm{C}$, was very low at $20^{\circ} \mathrm{C}$, and sporadic at $25^{\circ} \mathrm{C}$ (Fig. $1 \mathrm{~B}$ ). Using a $\beta$ function to fit the data (Table 1), it was determined that spore production and discharge were negligible at $\mathrm{T}<2.5^{\circ} \mathrm{C}$ and $\mathrm{T}>22^{\circ} \mathrm{C}$, and nearly absent at $\mathrm{T}>27^{\circ} \mathrm{C}$. This trend was consistent over the different incubation durations tested (data not shown).

Spore budding and temperature. After $12 \mathrm{~h}$ of incubation in water, ascospore budding (Fig. 2A) was sporadic at $0^{\circ} \mathrm{C}$, increased to a maximum at $10^{\circ} \mathrm{C}(0.79$ relative budding on average $)$, and progressively decreased until $25^{\circ} \mathrm{C}(0.51)$; thereafter, it strongly decreased to 0.09 at $30^{\circ} \mathrm{C}$ and to 0.02 at $37^{\circ} \mathrm{C}$. Relative blastospore budding (Fig. 2B) was 0.013 at $0^{\circ} \mathrm{C}$ and progressively increased to 0.8 at $20^{\circ} \mathrm{C}$. At higher $\mathrm{T}$, the budding activity progressively decreased to the minimum of 0.035 at $37^{\circ} \mathrm{C}$. These data both were fitted by a $\beta$ function (Table 1); the best fit for ascospores was obtained by fixing minimum and maximum $\mathrm{T}$ for budding at 0 and $40^{\circ} \mathrm{C}$, respectively; for blastospores the highest
$\mathrm{T}$ was $43^{\circ} \mathrm{C}$. Equations 3 and 5 (Table 1) for ascospores and blastospores, respectively, accounted for the differences between the two kinds of spores. Parameter $a$ is determinant for the maximum of the curve; parameter $b$ determines the steepness of the

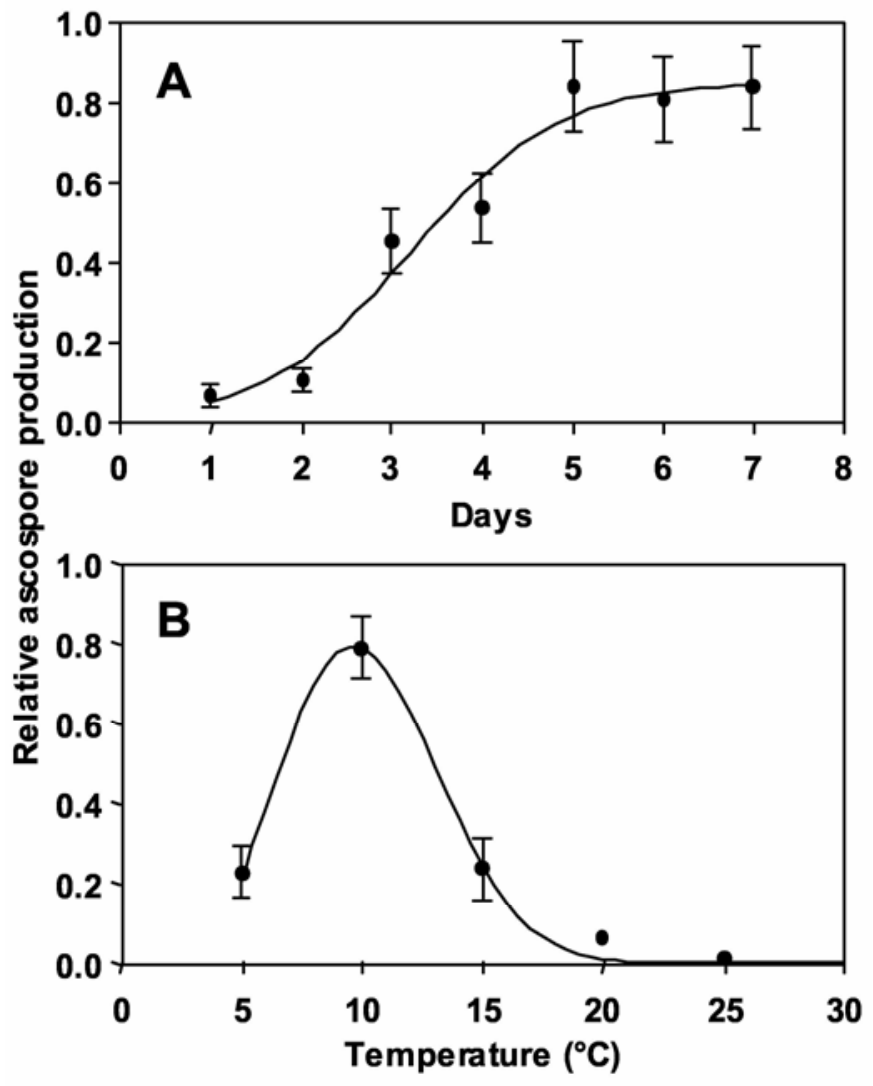

Fig. 1. Relative production of Taphrina deformans ascospores in discs of peach leaves affected by leaf curl. Leaves were incubated $\mathbf{A}$, at $10^{\circ} \mathrm{C}$ for 1 to 7 days or $\mathbf{B}$, at different temperatures for 7 days. Points are the means of 18 replicate leaves and bars represent their $95 \%$ confidence intervals. Ascospore production was estimated from the number of fungal colonies that developed from spores discharged from asci on leaf discs and expressed as relative production by the maximum possible number of colonies. Lines show the fit of the nonlinear $\mathbf{A}$, logistic and $\mathbf{B}, \boldsymbol{\beta}$ models to experimental data (equations 1 and 2 in Table 1).

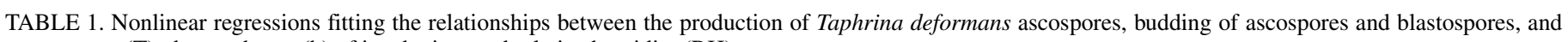
temperature $(\mathrm{T})$, days or hours $(\mathrm{h})$ of incubation, and relative humidity $(\mathrm{RH})$

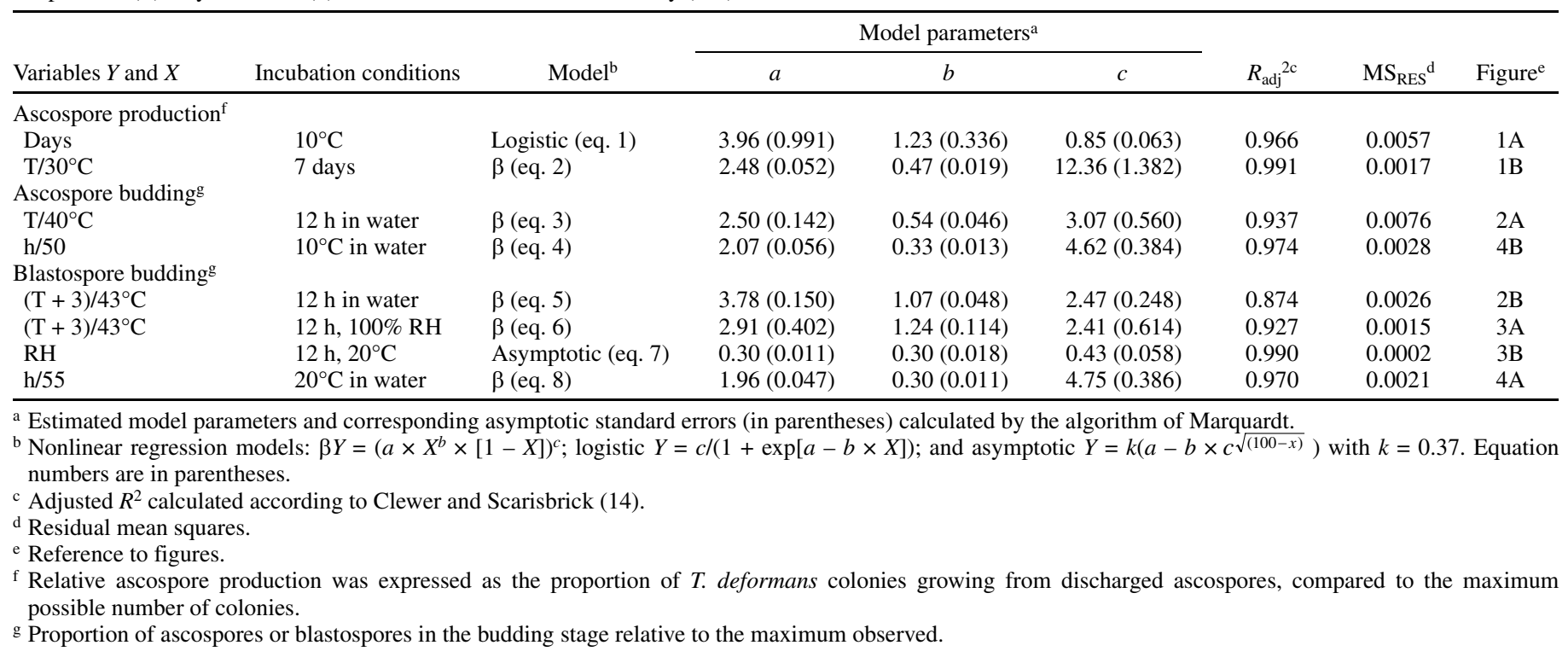


increasing phase and, therefore, the optimum level of the independent variable; whereas parameter $c$ is principally responsible for the width of the curve. In equations 3 and 5 , the biggest difference concerns $b$, which is 0.54 and 1.07, respectively, that reflects different optimum $\mathrm{T}$, which is $14^{\circ} \mathrm{C}$ for ascospores and $21^{\circ} \mathrm{C}$ for blastospores.

Spore budding and humidity. Over a dry substrate, at $100 \%$ $\mathrm{RH}$, blastospores were able to bud at all values of $\mathrm{T}$ tested, between 5 and $37^{\circ} \mathrm{C}$ (Fig. 3A). Compared with maximum budding observed in distilled water, budding activity of dry blastospores was 0.37 at optimum $\mathrm{T}$ of $20^{\circ} \mathrm{C}, \approx 0.25$ at 15 and $25^{\circ} \mathrm{C}, \approx 0.15$ at 10 and $30^{\circ} \mathrm{C}$ and, finally, very low at 5 and $37^{\circ} \mathrm{C}$. The shape of the curve that describes blastospore budding over $\mathrm{T}$ did not change much for wet and dry conditions, as demonstrated by the coefficients of the functions 5 and 6 in Table 1.

Reduction in $\mathrm{RH}$ strongly reduced budding of blastospores (Fig. 3B). At 97 and 95\% RH, budding was approximately three times lower than at $100 \% \mathrm{RH}$; at $47 \% \mathrm{RH}$, the reduction was greater than seven times. These data were fitted by the asymptotic equation 7 (Table 1); according to this equation, T. deformans blastospores also should maintain a certain budding activity at very low RH levels.

Spore budding and nutrient availability. The saprophytic development of $T$. deformans was studied as budding ability of blastoconidia grown (i) in the absence of nutrients, (ii) in the presence of limited nutrients, or (iii) in the presence of periodically renewed nutrients.

In the absence of nutrients, relative budding of blastoconidia was 0.16 after $2 \mathrm{~h}$ of incubation, and increased rapidly to a maximum after $10 \mathrm{~h}$ (Fig. 4A). Thereafter, budding progressively decreased to $<0.1$ after $48 \mathrm{~h}$. The best fit of the experimental data was obtained by the $\beta$ function 8 (Table 1 ): the calculated opti-

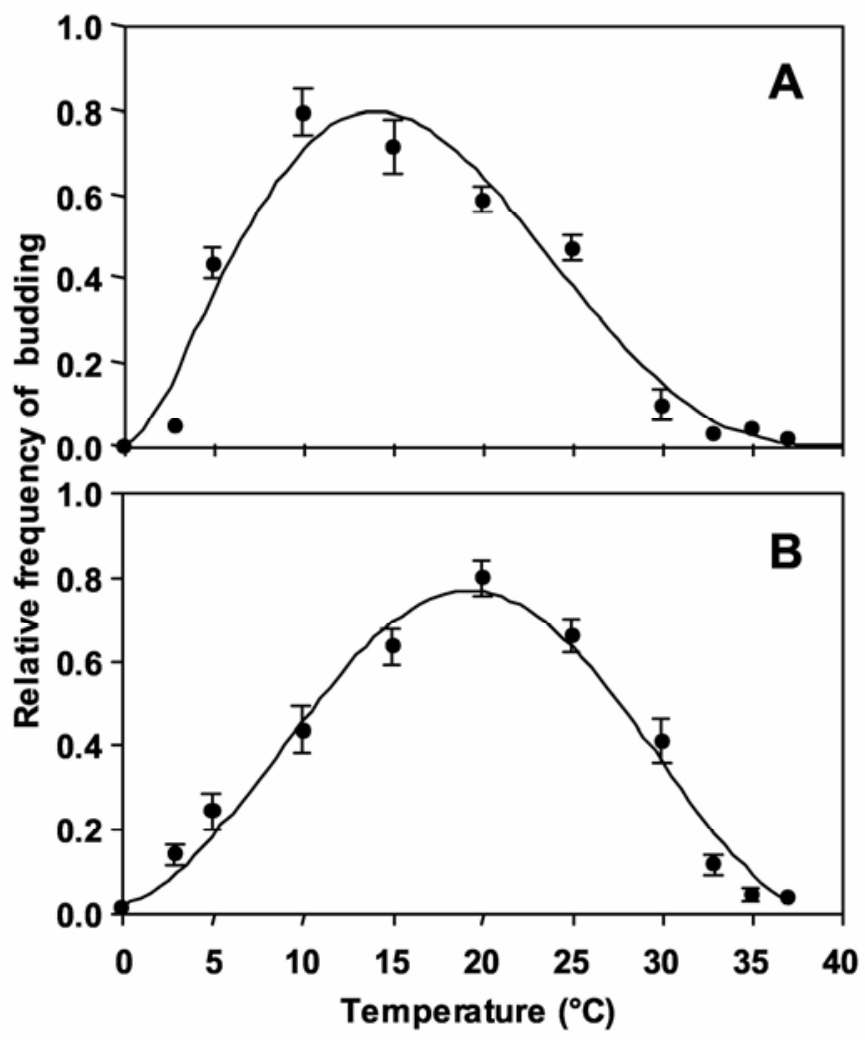

Fig. 2. Relative frequency of budding of Taphrina deformans A, ascospores and $\mathbf{B}$, blastospores incubated in distilled water for $12 \mathrm{~h}$ at different temperatures. Points are the means of 27 replicates and bars represent their $95 \%$ confidence intervals. The relative frequency was obtained by dividing by the observed maximum frequency of budding. Lines show the fit of the nonlinear $\beta$ model to experimental data (equations 3 and 5 in Table 1). mum time for spores to bud was $13 \mathrm{~h}$ and the maximum time was $55 \mathrm{~h}$ (Fig. 4A). Ascospores showed a very similar trend (Fig. 4B), and equations 4 and 8 had almost the same parameter values, with a maximum time of $50 \mathrm{~h}$.

In both experiments with the presence of a nutrient source, the budding ability was significantly $(P<0.0001)$ influenced by both nutrient concentration and incubation time, as well as by their interaction. In the presence of limited nutrient sources, budding after 6 and $12 \mathrm{~h}$ of incubation was higher in all the nutrient solutions than in distilled water, and budding increased with the increase in the solution concentration (Fig. 5A). After $24 \mathrm{~h}$, budding with nutrients again was higher than in water, but it was higher at the lowest than the highest nutrient concentrations. After 48 and $72 \mathrm{~h}$, budding occurred only for the lowest sugar concentrations and, after $72 \mathrm{~h}$, it was infrequent in all the treatments (Fig. 5A). When the nutrient solutions were renewed every $12 \mathrm{~h}$, initial budding increased with increasing sugar concentration in the nutrient solution; however, after $24 \mathrm{~h}$ of incubation, the budding activity decreased in distilled water and in the two solutions with the highest concentrations and ceased after 36 and 48 h, respectively (Fig. 5B). Fungal colonies grown in nutrient solutions with concentrations between $\times 1$ and $\times 10^{-3}$ maintained a constant budding activity until $96 \mathrm{~h}$ of incubation, with a lower relative budding for the lowest concentration (Fig. 5B).

\section{DISCUSSION}

In this work, the budding activity of both ascospores and blastospores of $T$. deformans was studied under different environmental conditions to determine the ability of the fungus to grow

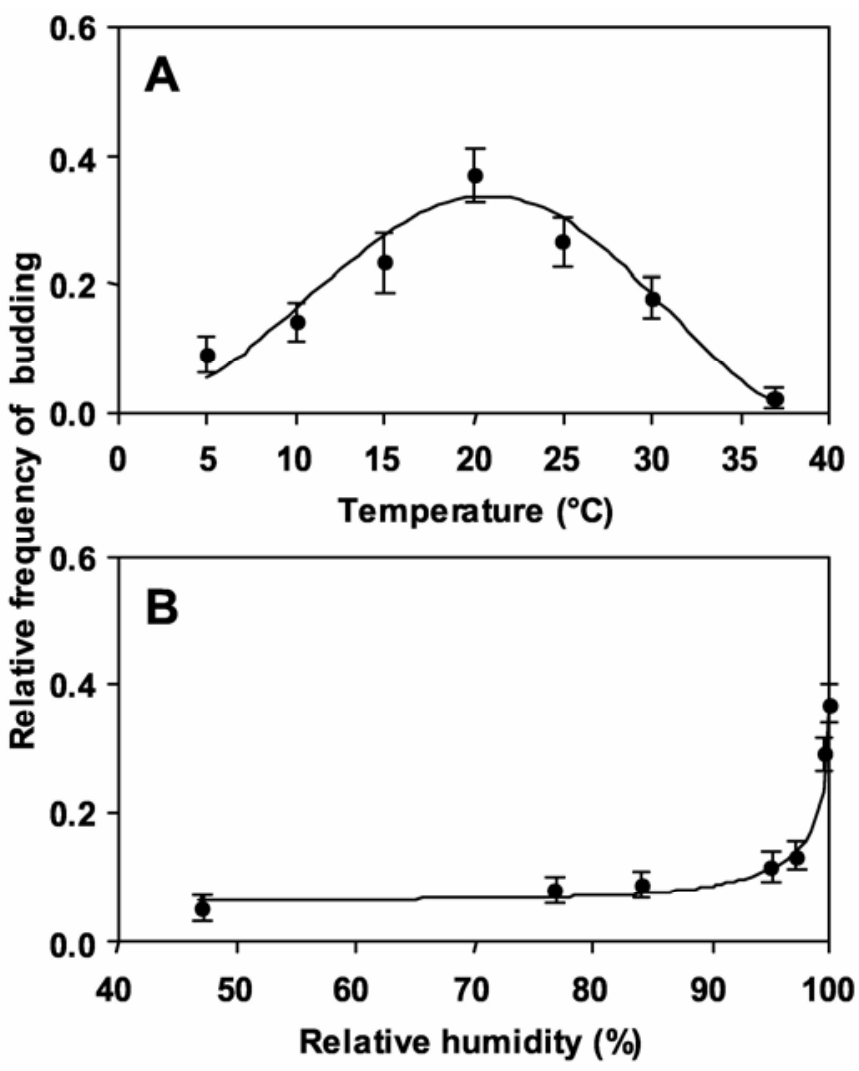

Fig. 3. Relative frequency of budding of Taphrina deformans blastospores incubated for $12 \mathrm{~h}$ at different temperatures $\mathbf{A}$, on a dry substrate at $100 \%$ relative humidity or $\mathbf{B}$, under different humidity regimes, at $20^{\circ} \mathrm{C}$. Points are means of 27 replicates and bars represent their $95 \%$ confidence intervals. The relative frequency was obtained by dividing by the maximum frequency of budding observed in distilled water at $20^{\circ} \mathrm{C}$. Lines show the fit of the nonlinear $\mathbf{A}, \beta$ and $\mathbf{B}$, asymptotic models to experimental data (equations 6 and 7 in Table 1). 
on peach plant surfaces as a component of the epiphytic microflora during the peach-growing season. Temperature, humidity, and nutrients were considered as key environmental elements in this work.

Budding of T. deformans spores occurred across a wide temperature range, with blastospores requiring a higher temperature than ascospores. Ascospore production and release also showed low temperature requirements. Results for blastospores were in perfect agreement with previously published literature $(3,23,24$, $28,32,41)$, but there are no previous reports of temperature relationships for ascospores. Therefore, the different response to temperature of blastospores and ascospores had never been documented before; however, it seems reasonable because the sexual stage usually occurs in spring when air temperature is relatively low (37). In northern Italy, the ascosporic stage usually occurs between April and mid-June, when air temperatures range between 7 to 10 and 20 to $24^{\circ} \mathrm{C}$, respectively (39).

In addition to temperature, humidity and nutrient availability also influenced budding. In the experiments performed here, the budding activity was approximately two-and-a-half times higher in a film of water than on a dry substrate with $100 \% \mathrm{RH}$. Measurable budding at 95 to $100 \% \mathrm{RH}$ previously had been observed by Lorenz (29), but this work demonstrated that blastospores also maintain the ability to bud at lower levels of RH.

Concerning nutrients, it has been demonstrated that the fungus thrives in culture in a wide variety of media, many of them of low nutritional content $(17,24,41)$, or in dilute solutions of peach gum (33) or on shoot tips (11). Based on this evidence, Mix (33) stated that it is difficult to believe that the fungus may not find opportunities for saprophytic growth in solutions naturally occurring on peach tree surfaces, and there seems to be no reason to exclude

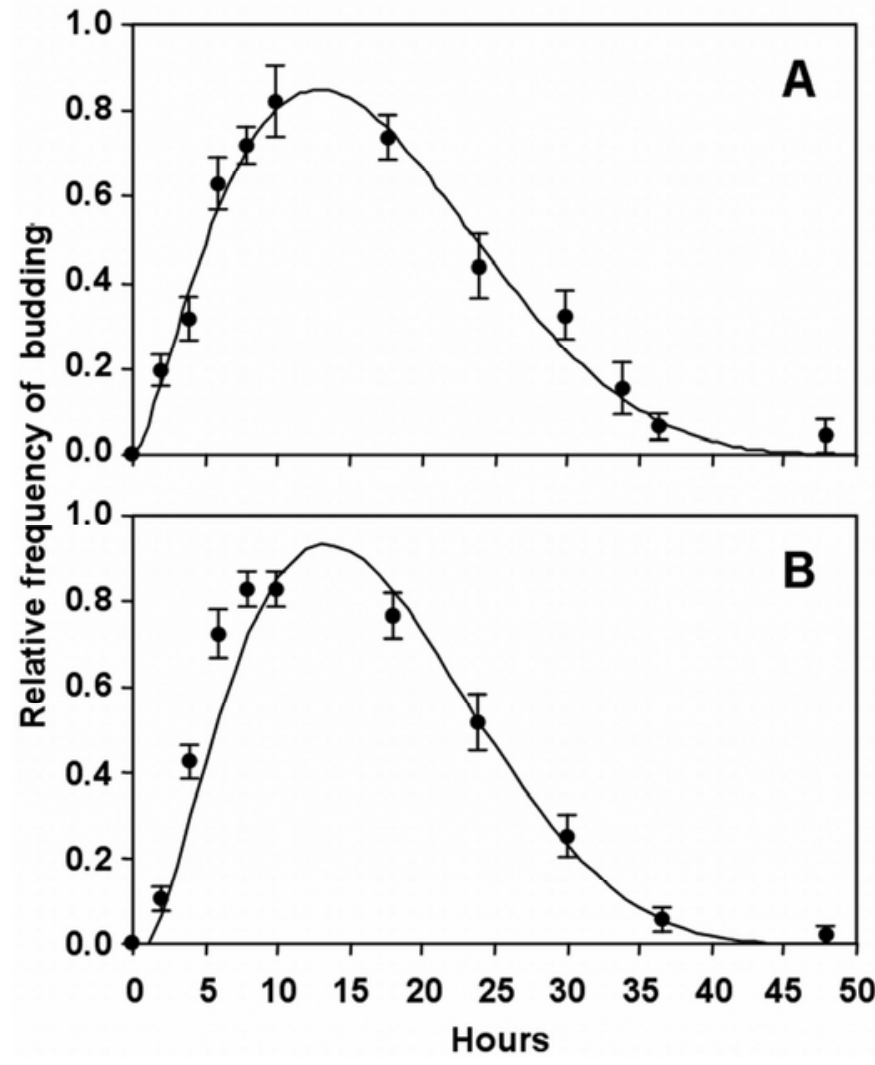

Fig. 4. Relative frequency of budding of Taphrina deformans A, blastospores and $\mathbf{B}$, ascospores over time at $20^{\circ} \mathrm{C}$ in distilled water. Points are means of 27 replicates and bars represent their $95 \%$ confidence intervals. The relative frequency was obtained by dividing by the observed maximum frequency of budding. Lines show the fit of the nonlinear $\beta$ model to experimental data (equations 4 and 8 in Table 1). any part of the surface of the peach tree as a potential site of colonization.

Leaf surfaces may play an important role in the epiphytic behavior of the fungus, leaves representing the greatest surface area for possible colonization during peach growth. In general, the loss of nutrients from the leaf to the phyllosphere seems to be quantitatively limited (45); nevertheless, it supports the growth of many epiphytic microorganism populations $(5,21)$ and, particularly, yeasts, which are active colonists of leaves $(4,19)$. Epiphytic colonization of Prunus leaves has been demonstrated for hyphal fungi, yeasts, and bacteria $(42,44,51)$.

Caporali (13) obtained T. deformans colonies from peach leaves. Schneider and René (41) cultured the fungus on agar containing $1 \%$ of the sugars present on the peach surfaces. The fungus used sucrose, glucose, and fructose better than other carbon sources, including sorbitol, which is the prevalent sugar in

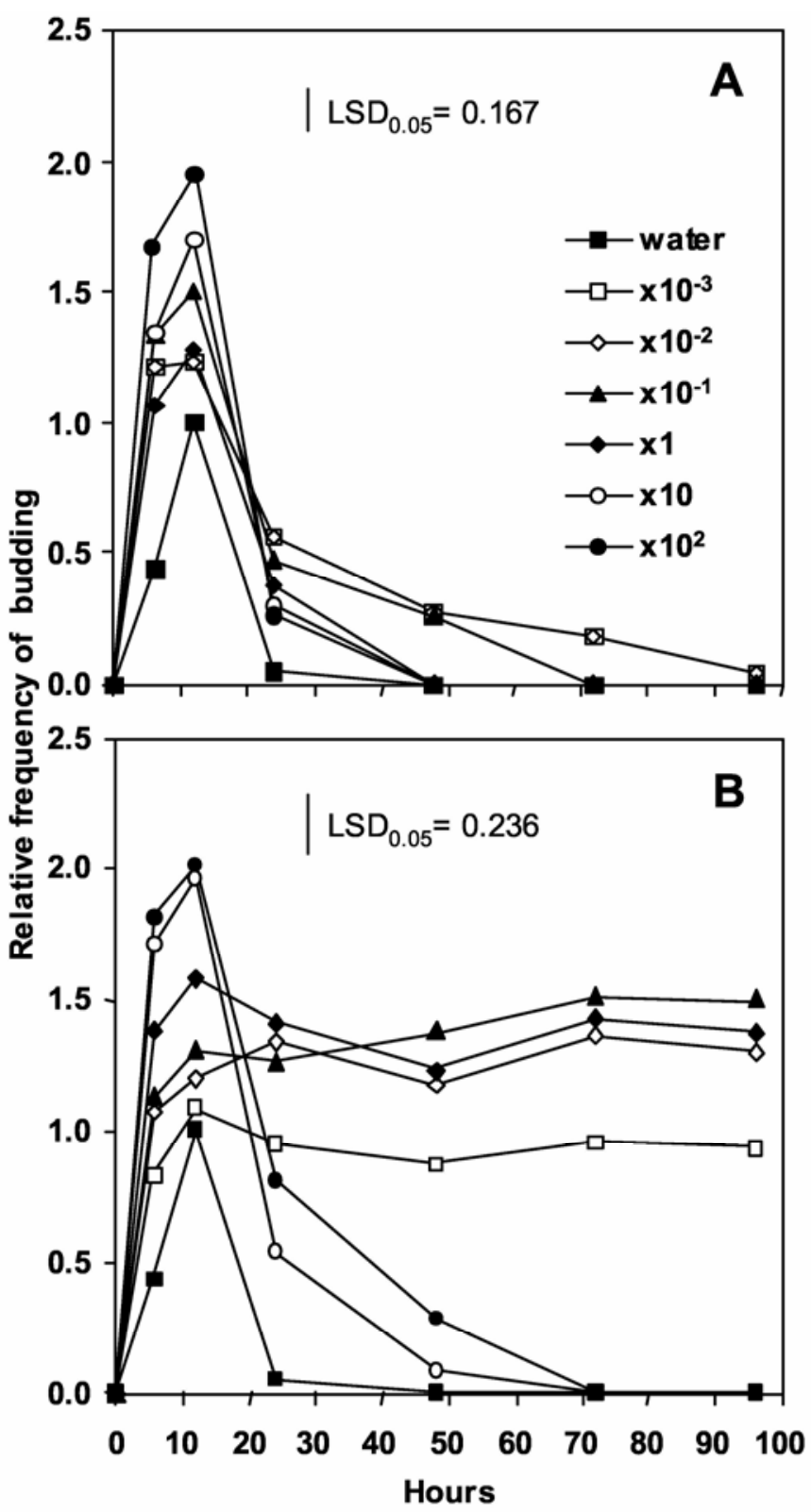

Fig. 5. Relative frequency of budding of Taphrina deformans blastospores over time of incubation at $20^{\circ} \mathrm{C}$ in distilled water and in nutrient solutions containing simple sugars at different concentrations $\left(\times 10^{-3}\right.$ to $\left.10^{2}\right)$. A, Nutrient solutions were not renewed, and $\mathbf{B}$, nutrients were renewed every $12 \mathrm{~h}$ of incubation. The relative frequency was obtained by dividing by the maximum frequency of budding observed in distilled water. Bars are the least significant differences (LSD) at $P=0.05(n=27)$. 
peach leaves and in phloem exudates $(16,36)$, and is present on peach fruit surfaces at appreciable concentration (20). In contrast, Lorenz (29) observed only a small growth of T. deformans on detached peach leaves and in leaf washings, and stated that growth was limited by an insufficient concentration of carbon sources. Lorenz's results cannot be considered conclusive because the experimental design did not include a control in distilled water to be used for comparing the observed growth occurring in total lack of nutrients. In addition, it seems unlikely that nutrient abundance as averaged over an entire leaf surface is of any relevance to an epiphytic colonizer, due to the fact that the nutrient availability on leaves is heterogeneous, with some locations having a relative abundance due to accumulation or higher leakage, such as in the proximity of stomata, along veins, near the base of glandular trichomes, or sites of injury (26).

In the experiments described here, $T$. deformans colonies developed from both ascospores and blastospores cultured in the absence of external nutrients ceased to grow after $\approx 50$ to $55 \mathrm{~h}$. In the presence of simple sugars, the fungus initially budded at higher frequencies but progressively lost its budding ability, more rapidly with higher nutrient concentrations than in the more diluted ones. When nutrient solutions were renewed every $12 \mathrm{~h}$, the fungus maintained its budding capability over time. These results showed that $T$. deformans spores contain nutrients that allow an initial growth in the absence of external carbon sources; however, external nutrients become necessary to support the longtime growth of fungal colonies. When nutrients were not renewed, the budding capability declined after $12 \mathrm{~h}$ and was absent after 48 to $72 \mathrm{~h}$. Various authors have observed the inhibition of growth in some yeastlike fungi due to metabolites produced by the fungal colony itself, with particular attention to methanol $(30,46)$. Although the fermentative ability of genus Taphrina has not been reported (47), it cannot be excluded that the budding decline could be caused by an accumulation of fungal metabolites.

The sugars on peach leaf and fruit surfaces can support saprophytic growth of $T$. deformans at the low concentrations found on surfaces of some plant leaves $(31,45)$ and peach fruit $(20)$. On tree surfaces, the plant metabolism likely provides for a regular efflux of nutrients and free water from rainfall or dew dilutes the fungal metabolites, causing an inhibitory effect on spore budding. Production of the plant growth regulator indole-3-acetic acid (IAA) by $T$. deformans (49) probably increases its ability to grow on plant surfaces; in fact, it has been demonstrated that microbial epiphytes producing IAA have an increased ability to colonize plant surfaces (27), likely because of an increase in nutrient availability due to IAA-stimulated release of saccharides from plant cells (22).

Bud scales, which are the most important niches occupied by T. deformans cells, are likely very hospitable, as demonstrated by the fact that they have a high microbial carrying capacity $(7,25$, $32,43)$. Bud pubescence favors the retention of spores that move on bud scales and also maintains high humidity for long periods. Furthermore, buds develop at the axilla of leaves and likely receive water from the leaf blades via the leaf stem. In P. persica, stems, petioles, and stipules, which are in close contact with buds, are rich in extrafloral nectaries that excrete fluids containing high concentrations of sugars (8) that can increase concentration of nutrients on scales.

In conclusion, $T$. deformans is able to bud under a wide range of temperatures in the presence of water, and a certain amount of growth also is possible at low RH. At the concentrations of nutrients that typically are present on peach plant surfaces, the fungus maintains its budding capability over time. Therefore, results from the present work support the idea that the fungus is a part of the normal surface mycoflora of peach trees (17). The epidemiological consequence of this result is that blastospores can multiply for a long time during the season and the inoculum dose can increase within the orchard at a variable rate depending on weather conditions. Nevertheless, this inoculum is able to withstand high or low temperatures and desiccation long enough to survive unfavorable periods $(24,29,32)$.

\section{ACKNOWLEDGMENTS}

This work is part of research promoted and supported by the EmiliaRomagna Region (Italy) in cooperation with the Centro Ricerche Produzioni Vegetali (CRPV).

\section{LITERATURE CITED}

1. Agrios, G. N. 1988. Plant Pathology. Academic Press Inc., New York.

2. Analytis, S. 1977. Über die relation zwischen biologischer entwicklung und temperatur bei phytopathogene pilzen. Phytopathol. Z. 90:64-76.

3. Anderson, H. W. 1956. Disease of Fruit Crops. McGraw-Hill Book Company Inc., New York.

4. Andrews, J. H., and Harris, R. F. 2000. The ecology and biogeography of microorganisms on plant surfaces. Annu. Rev. Phytopathol. 38:145-180.

5. Bakeman, J. P. 1973. The chemical environment of the leaf surface with special reference to spore germination of pathogenic fungi. Pestic. Sci. 4:575-588.

6. Bassi, M., Conti, G. G., and Barbieri, N. 1984. Cell wall degradation by Taphrina deformans in host leaf cells. Mycopathologia 88:115-125.

7. Buck, J. W., Lachance, M. A., and Traquair, J. A. 1998. Mycoflora of peach bark: Population dynamics and composition. Can. J. Bot. 76:345354.

8. Caldwell, D. L., and Gerhardt, K. O. 1986. Chemical analysis of peach extrafloral nectary exudate. Phytochemistry 25:411-413.

9. Campbell, C. L., and Madden, L. V. 1990. Introduction to Plant Disease Epidemiology. John Wiley \& Sons Ltd., New York.

10. Caporali, L. 1961. Sur l'origine des conidies de Taphrina deformans (Berk.) Tul. vivant a la surface des rameaux de Prunus persica L. C. R. Acad. Sci. Paris 253:890-891.

11. Caporali, L. 1965. Le comportement du Taphrina deformans (Berk.) Tul. in vitro. Rev. Cytol. Biol. Veg. 28:303-413.

12. Caporali, L. 1966. Nouvelles observations sur la biologie et sur le parasitisme du Taphrina deformans (Berk.) Tul. Proc. 1st Congr. Mediterr. Phytopathol. Union 1:36-42.

13. Caporali, L. 1974. Evolution des méthodes de sélection et d'identification des spores fongiques présentes à la surface d'arbres fruitiers. C. R. Acad. Sci. Paris 278:2743-2746.

14. Clewer, A. G., and Scarisbrick, D. H. 2001. Practical Statistics and Experimental Design for Plant and Crop Science. John Wiley \& Sons Ltd., New York.

15. Dhingra, O. D., and Sinclair, J. B. 1985. Basic Plant Pathology Methods. CRC Press, Inc., Boca Raton, FL.

16. Escobar-Gutierrez, A., and Gaudilliere, J. P. 1994. Variability in sorbitol: sucrose ratio in mature leaves of different peach cultivars. J. Am. Soc. Hortic. Sci. 119:321-324.

17. Fitzpatrick, R. E. 1934. The life history and parasitism of Taphrina deformans. Sci. Agric. 14:305-326.

18. Fitzpatrick, R. E. 1935. Further studies on the parasitism of Taphrina deformans. Sci. Agric. 15:341-344.

19. Fokkema, N. J., and Schippers, B. 1986. Phyllosphere versus rhizosphere as environment for saprophytic colonization. Pages 137-159 in: Microbiology of the Phyllosphere. N. J. Fokkema and J. Van Den Heuvel, eds. Cambridge University Press, Cambridge, UK.

20. Fourie, J. F., and Holz, G. 1998. Effects of fruit and pollen exudates on growth of Botrytis cinerea and infection of plum and nectarine fruit. Plant Dis. 82:165-170.

21. Frossard, R. 1981. Effect of guttation fluids on growth of microorganisms on leaves. Pages 231-226 in: Microbial Ecology of the Phylloplane. J. P. Bakeman, ed. Academic Press, London.

22. Fry, S. C. 1989. Cellulases, hemicelluloses and-auxin-stimulated growth: A possible relationship. Physiol. Plant. 75:532-536.

23. Ghillini, C. A. 1952. I Parassiti Vegetali delle Piante: Tafrinacee italiane. Edizioni Agricole, Bologna, Italy.

24. Ko, Y., Sun, S. K., and Pan, C. M. 1998. Studies on physiological characteristics and survival of peach leaf curl pathogen, Taphrina deformans, in vitro. Plant Prot. Bull. Taipei 40:351-360.

25. Leben, C. 1971. The bud in relation to the epiphytic mycoflora. Pages 117-127 in: Ecology of Leaf-Surface Micro-Organisms. T. F. Preece and C. H. Dickinson, eds. Academic Press, London.

26. Leveau, J. H. J., and Lindow, S. E. 2001. Appetite of an epiphyte: Quantitative monitoring of bacterial sugar consumption in the phyllosphere. Proc. Natl. Acad. Sci. USA 98:3446-3453.

27. Lindow, S. E., and Brandl, M. T. 2003. Microbiology of the phyllosphere. 
Appl. Environ. Microbiol. 69:1875-1883.

28. Lorenz, D. H. 1976. Beiträge zur Kenntnis der natürlichen Variabilität under der Physiologie von Taphrina deformans (Berk.) Tul. Phytopathol. Z. 85:117-131.

29. Lorenz, D. H. 1976. Beiträge zur weiteren Kenntnis des Lebenszyklus von Taphrina deformans (Berk.) Tul. unter besonderer Berücksichtigung der Saprophase. Phytopathol. Z. 86:1-15.

30. Medawar, W., Strehaiano, P., and Délia, M. L. 2003. Yeast growth: Lag phase modelling in alcoholic media. Food Microbiol. 20:527-532.

31. Mercier, J., and Lindow, S. E. 2000. Role of leaf surface sugars in colonization of plants by bacterial epiphytes. Appl. Environ. Microbiol. 66:369-374.

32. Mix, A. J. 1924. Biological and cultural studies of Exoascus deformans. Phytopathology 14:217-233.

33. Mix, A. J. 1935. The life history of Taphrina deformans. Phytopathology 25:41-66.

34. Mix, A. J. 1949. A monograph of the genus Taphrina. Sci. Bull. 33:3-167.

35. Moing, A., Carbonne, F., Rashad, M. H., and Gaudillere, J. P. 1992. Carbon fluxes in mature peach leaves. Plant Physiol. 100:1878-1884.

36. Moing, A., Carbonne, F., Zipperlin, B., Svanella, L., and Gaudillere, J. P. 1997. Phloem loading in peach: Symplastic or apoplastic? Physiol. Plant. 101:489-496.

37. Pscheidt, J. W. 1995. Leaf curl. Page 22 in: Compendium of Stone Fruit Diseases. J. M. Ogawa, E. I. Zehr, G. W. Bird, D. F. Ritchie, K. Uriu, and J. K. Uyemoto, eds. The American Phytopathological Society, St. Paul, MN.

38. Quinn, G. P., and Keough, M. J. 2002. Experimental Design and Data Analysis for Biologists. Cambridge University Press, Cambridge, UK.

39. Rossi, V., Bolognesi, M., Languasco, L., and Giosuè, S. 2006. Influence of environmental conditions on infection of peach shoots by Taphrina deformans. Phytopathology 96:155-163.

40. Schneider, A. 1966. Les variations annuelles de la proline chez le Pêcher.
C. R. Acad. Sci. Paris 262:2726-2729.

41. Schneider, A., and René, J. 1969. Influence des conditions physiques et nutritives sur le développement de Taphrina deformans en culture in vitro. C.R. Acad. Sci. Paris 268:44-47.

42. Shepard, D. P., and Zehr, E. I. 1994. Epiphytic persistence of Xanthomonas campestris pv. pruni on peach and plum. Plant Dis. 78:627629.

43. Tavares S., Inácio J., Fonseca, Á., and Oliveira, C. 2004. Direct detection of Taphrina deformans on peach using molecular methods. Eur. J. Plant Pathol. 110:973-982.

44. Teviotdale, B. L., and Hendricks, L. 1994. Survey of mycoflora inhabiting almond fruit and leaves in conventionally and organically farmed orchards. Acta Hortic. 373:177-183.

45. Tukey, H. B., Jr. 1970. The leaching of substances from plants. Annu. Rev. Plant Physiol. 21:305-324.

46. van Uden, N. 1985. Ethanol toxicity and ethanol tolerance in yeasts. Annu. Rep. Ferment. Processes 8:11-58.

47. Verona, O., and Rambelli, A. 1962. Notizie intorno ai caratteri di alcune specie di Taphrina in fase saprofitaria (Saprotaphrina). Ann. Fac. Agrar. (Univ. Pisa) 23:1-36.

48. XueFeng, G., ShaoHua, L., GuoJie, L., ZhanFang, F., and SongTao, L. 2004. Seasonal changes in carbohydrate content and related enzyme activity in fruit and leaves of 'Yanfengyihao' peach variety. J. Fruit Sci. 21:196-200.

49. Yamada, T., Tsukamoto, H., Shiraishi, T., Nomura, T., and Oku, H. 1990. Detection of indoleacetic acid biosynthesis in some species of Taphrina causing hyperplastic diseases in plants. Ann. Phytopathol. Soc. Jpn. 56:532-540.

50. Yarwood, C. E. 1941. The diurnal cycle of ascus maturation of Taprhina deformans. Am. J. Bot. 28:355-357.

51. Young, J. M. 1978. Survival of bacteria on Prunus leaves. Pages 779-786 in: Proc. Fourth Int. Conf. Plant-Pathogenic Bacteria, Florence, Italy. 